\title{
The Metabolism of Orally and
}

\section{Intravenously Administered Labeled}

\author{
Aldosterone in Pregnant Subjects
}

\author{
J. F. TAIT and B. LrTtre \\ with the technical assistance of C. FLOOD and S. WiLloughBY \\ From the Worcester Foundation for Experimental Biology, \\ Shrewsbury, Massachusetts 01545; and the Department of Reproductive \\ Biology, Case Western Reserve University School of Medicine, and \\ the Department of Obstetrics and Gynecology, Cleveland \\ Metropolitan General Hospital, Cleveland, Ohio 44100
}

A B STRACT Aldosterone metabolism has been shown to be altered in pregnancy. The increased conversion of intravenously administered aldosterone- ${ }^{-3} \mathrm{H}$ to the acid-labile conjugate in the urine (aldosterone 18-glucuronide) has again been observed. The urinary yield of intravenously administered aldosterone- ${ }^{3} \mathrm{H}$ as aldosterone 18-glucuronide in 16 pregnant subjects of $13.4 \pm 0.9$ (SE) \% was significantly higher $(P<0.001)$ than in 11 nonpregnant subjects (seven males and four females) of $7.3 \pm 0.5$ ( $\mathrm{sE}) \%$.

After combining oral $\left({ }^{14} \mathrm{C}\right)$ and intravenous $\left({ }^{3} \mathrm{H}\right)$ administration of aldosterone, the ${ }^{14} \mathrm{C} /{ }^{3} \mathrm{H}$ ratios of urinary metabolites (free aldosterone, tetrahydroaldosterone glucuronide, and aldosterone 18-glucuronide) were measured and were expressed as a per cent of administered dose. From these data the splanchnic extraction of aldosterone was calculated. The splanchnic extraction was significantly lower in pregnant as compared to nonpregnant subjects, although previous work indicated no change in protein binding of aldosterone in pregnancy.

However, the data on the ${ }^{14} \mathrm{C} /{ }^{3} \mathrm{H}$ ratio of other metabolites suggested that a large part of the increased aldosterone 18-glucuronide metabolite in pregnancy is formed in the splanchnic circulation; also, there appeared to be increased tetrahydro-

Received for publication 16 October 1967 and in revised form 12 July 1968. aldosterone glucuronide formation extrasplanchnically.

\section{INTRODUCTION}

Aldosterone metabolism was shown to be altered in pregnancy (1). The validity of this observation was questioned by Watanabe, Meeker, Gray, Sims, and Solomon (2). The present paper confirms the original observations and presents additional data to suggest possible mechanisms for this altered metabolism in pregnancy.

Jones, Lloyd-Jones, Riondel, Tait, Tait, Bulbrook, and Greenwood (1) reported a higher excretion of aldosterone released by mild acid treatment of urine (now presumed to be aldosterone 18-glucuronide) from pregnant compared with nonpregnant subjects. They suggested that this was partially due to the increased conversion of secreted aldosterone to his metabolite. Subsequently Watanabe and coworkers (2) studied the metabolism of aldosterone in four pregnant subjects but were unable to confirm this observation of altered conversion. We therefore reinvestigated this problem by administering intravenously aldosterone- $7-{ }^{3} \mathrm{H}$ to six pregnant subject and then measuring the radioactive yield to three urinary fractions: free aldosterone, aldosterone released from the acid-labile conjugate (hereafter presumed to be aldosterone 18-glucuronide [3]) and tetra- 
hydroaldosterone released by incubation with $\beta$-glucuronidase. ${ }^{1}$ These studies, described herein, have confirmed the results of Jones and coworkers (1).

In addition, oral aldosterone- $4-{ }^{14} \mathrm{C}$ and intravenous aldosterone- $7-{ }^{3} \mathrm{H}$ were given simultaneously to 10 other pregnant subjects, and the radioactive yield to the three urinary fractions from both administered doses was observed. The aim of this approach was to determine the site of and possibly the mechanism for the increased formation of aldosterone 18-glucuronide in pregnancy. Also, from such data the splanchnic extraction of aldosterone in pregnancy could be calculated $(4,5)$.

\section{METHODS}

The pregnant subjects (all in the last trimester) were patients at the Cleveland Metropolitan General Hospital or the Boston City Hospital. 10 pregnant women (Table I) aged 17-31 $\mathrm{yr}$ were admitted as volunteers to the

1 Trivial names : 17 -isoaldosterone $=11 \beta, 21$-dihydroxy18-oxo-17-isopregn-4-en-20-one ; tetrahydroaldosterone $=$ $3 \alpha, 11 \beta, 21$-trihydroxy-18-oxo-5 $\beta$-pregnan-20-one ; aldosterone 18-glucuronide $=21$-hydroxy-11: 18 -oxidopregn-4-ene3,20-dion-18-yl- $\beta$-D-glucopyranosiduronic acid; 17 -isoaldosterone-18-glucuronide $=21$-hydroxy-11 : 18-oxido-17isopregn-4-ene-3,20-dione-18-glucopyranosiduronic acid.
Perinatal Research Unit. The six other pregnant subjects were studied during a hospital admission for unrelated problems. The four nonpregnant female subjects were in the age range, 23-32 yr. M.E. and C.K. were both in the proliferative phase of their menstrual cycles at the time of investigation. J.F. was menstruating, and P.W. was at mid-ovarian cycle. All were on a normal uncontrolled diet (Table I).

The radioactive steroids were administered at 10 a.m. Thereafter the subjects were allowed to walk freely about the ward. Urine was collected for $48 \mathrm{hr}$ after administration of labeled aldosterone. A single intravenous injection of $2.0 \mu \mathrm{c}$ of aldosterone-7- ${ }^{3} \mathrm{H}$ was given to six pregnant subjects. A combined oral and intravenous dose of aldosterone was given to an additional 10 pregnant and four nonpregnant women. The oral dose was $0.5 \mu \mathrm{c}$ of aldosterone- $-4-{ }^{14} \mathrm{C}$, and the intravenous injection was 2.0 $\mu \mathrm{c}$ of aldosterone- $7-{ }^{8} \mathrm{H}$ as a single injection. The yields of administered radioactivity from aliquots of the 48-hr collections of urine as free aldosterone, as aldosterone released from aldosterone 18-glucuronide by mild acid hydrolysis, and as tetrahydroaldosterone released by $\beta$-glucuronidase incubation were measured. Details of the administration of the steroid and the analysis of the urine are as previously described by Flood, Pincus, Tait, Tait, Willoughby, Layne, Ramcharan, and Rossipal (5, 6) except for the measurement of the yield of administered radioactivity as urinary free aldosterone. In previous studies with normal and elderly subjects (including two of the nonpregnant females), the ${ }^{14} \mathrm{C} /{ }^{3} \mathrm{H}$ ratio was constant throughout the column fractions containing the measured metabolites including the free aldosterone,

TABLE I

Clinical Data

\begin{tabular}{|c|c|c|c|c|c|c|c|c|c|c|}
\hline \multirow[b]{2}{*}{ Subject } & \multirow[b]{2}{*}{ Age } & \multirow[b]{2}{*}{ Weight } & \multirow[b]{2}{*}{ Height } & \multirow[b]{2}{*}{ Het } & \multirow{2}{*}{$\begin{array}{c}\text { Blood } \\
\text { pressure }\end{array}$} & \multirow{2}{*}{$\begin{array}{l}\text { Gestation } \\
\text { at test }\end{array}$} & \multicolumn{3}{|c|}{ Estrogen excretion } & \multirow[b]{2}{*}{ Remarks } \\
\hline & & & & & & & Estrone & Estradiol & Estriol & \\
\hline & $y r$ & kg & $\mathrm{cm}$ & $\%$ & $m m \mathrm{Hg}$ & $w k$ & & $\mu g / 2+h r$ & & \\
\hline \multicolumn{11}{|l|}{ Pregnant } \\
\hline B. K. & 26 & 52.0 & 155 & 34 & $126 / 70$ & 31 & 220 & 100 & 4100 & $\mathrm{Wt}$ gain $11.4 \mathrm{~kg}$ \\
\hline V. M. & 19 & 65.0 & 160 & 33 & $110 / 70$ & 35 & 440 & 130 & 4800 & Wt gain $5.2 \mathrm{~kg}$ \\
\hline I.P. & 29 & 77.5 & 167 & 31 & $134 / 80$ & 37 & 300 & 120 & 8700 & Wt gain $17.5 \mathrm{~kg}$ \\
\hline J. S. & 17 & 59.0 & 163 & 35 & $118 / 72$ & 32 & 950 & 240 & 3000 & Wt gain $6.8 \mathrm{~kg}$ \\
\hline M. N. & 21 & 57.3 & 157 & 40 & $130 / 80$ & 34 & 360 & 160 & 3300 & Wt gain $7.7 \mathrm{~kg}$ \\
\hline A. N. & 31 & 78.6 & 156 & 38 & $120 / 70$ & 36 & 170 & 90 & 5800 & $W t$ gain $13.6 \mathrm{~kg}$ \\
\hline D. J. & 30 & 99.8 & 155 & 36 & $130 / 80$ & 36 & 900 & 300 & 9000 & Wt gain unknown \\
\hline R. C. & 29 & 64.2 & 163 & 32 & $100 / 70$ & 31 & 340 & 90 & 4100 & Wt gain $10.0 \mathrm{~kg}$ \\
\hline G. N. & 18 & 48.0 & 152 & 39 & $102 / 79$ & 36 & 1100 & 260 & 4300 & $W t$ gain $3.2 \mathrm{~kg}$ \\
\hline B. G. & 22 & 63.2 & 160 & 37 & $100 / 70$ & 32 & 730 & 210 & 3500 & Wt gain $14.3 \mathrm{~kg}$ \\
\hline Nonpregnant & & & & & & & & & & . \\
\hline M. E. : & 32 & 66.5 & 155 & 34 & $122 / 88$ & - & - & - & - & Menstrual cycle day 7 \\
\hline C. $\mathrm{K}$. & 23 & 55.9 & 165 & 37 & $120 / 70$ & - & - & - & 一 & Menstrual cycle day 4 \\
\hline J.F. & 36 & 68.2 & 172 & 一 & - & - & - & - & 一 & $\begin{array}{l}\text { Menstrual cycle day } \\
10-15\end{array}$ \\
\hline P. W. & 26 & 61.8 & 168 & 45 & $124 / 86$ & - & - & - & - & $\begin{array}{l}\text { Menstrual cycle day } \\
24-28\end{array}$ \\
\hline
\end{tabular}


which indicated the radiochemical purity of the isolated material. However, when free aldosterone from the urine from pregnant subjects was examined by this method, the ${ }^{14} \mathrm{C} /{ }^{8} \mathrm{H}$ ratio was not uniform in the fractions from the column containing free aldosterone. Therefore all these fractions were taken to dryness, acetylated, and the aldosterone diacetate purified on another column (60 $\mathrm{cm}$ long, $1 \mathrm{~cm}$ diameter toluene: Skellysolve (Skelly Oil Co., Tulsa, Okla.), $2: 3.5$; mobile phase; methanol: water, 4:1 stationary phase). The ${ }^{14} \mathrm{C} /{ }^{3} \mathrm{H}$ ratios in the fractions containing aldosterone diacetate were then satisfactorily constant. After administration of intravenous aldosterone- $7-{ }^{8} \mathrm{H}$ and oral aldosterone- $4-{ }^{14} \mathrm{C}$ to two nonpregnant female subjects, the ${ }^{14} \mathrm{C} /{ }^{3} \mathrm{H}$ ratios of the urinary free aldosterone, measured finally as the diacetate by the same method, was 0.110 and 0.010 , which were not significantly different than the values previously estimated for normal subjects (mean 0.037 , range $0.014-0.063$ for seven male subjects, 0.07 and 0.07 for two nonpregnant females) when only one column was used for purification without acetylation.

\section{RESULTS}

For the six pregnant subjects given an intravenous injection of labeled aldosterone without simultaneous oral administration, the $48 \mathrm{hr}$ urinary yield of administered dose as aldosterone 18-glucuronide was $13.1 \pm 1.8$ (SE) \% compared with $7.6 \pm 1.0$ (SE) \% for four nonpregnant females and $7.1 \pm 0.7$ (SE) \% for 7 males (Table II). The urinary yield was therefore significantly higher for pregnant compared with either group of non-

TABLE II

Conversion of $2.0 \mu \mathrm{C}$ of Intravenous Aldosterone-7-3 $\mathrm{H}$ and $0.5 \mu \mathrm{C}$ of Oral Aldosterone-4-14C to Urinary Free Aldosterone, Acid-Released Aldosterone, and $\beta$-Glucuronidase-Released Tetrahydroaldosterone for Pregnant and Nonpregnant Female and Male Subjects

\begin{tabular}{|c|c|c|c|c|c|c|}
\hline \multirow[b]{2}{*}{ Subjects } & \multicolumn{2}{|c|}{ Free aldosterone } & \multicolumn{2}{|c|}{ Acid-released aldosterone } & \multicolumn{2}{|c|}{$\begin{array}{l}\beta \text {-Glucuronidase-released } \\
\text { tetrahydroaldosterone }\end{array}$} \\
\hline & $\begin{array}{l}{ }^{14} \mathrm{C} /{ }^{3} \mathrm{H} \\
\times 100 \% * \\
(\mathrm{r})\end{array}$ & $\begin{array}{c}\text { Hepatic } \\
\text { extraction } \\
\text { per cent } \\
(1-r)\end{array}$ & $\begin{array}{l}{ }^{3} \mathrm{H} \text { per cent of } \\
\text { intravenous } \\
\text { dose }\end{array}$ & $\begin{array}{l}{ }^{14} \mathrm{C} /{ }^{3} \mathrm{H} \\
\times 100 \% *\end{array}$ & $\begin{array}{l}{ }^{3} \mathrm{H} \text { per cent of } \\
\text { intravenous } \\
\text { dose }\end{array}$ & $\begin{array}{l}{ }^{14} \mathrm{C} /{ }^{2} \mathrm{H} \\
\times 100 \% *\end{array}$ \\
\hline \multicolumn{7}{|l|}{ Female } \\
\hline \multicolumn{7}{|l|}{ Pregnant } \\
\hline B. $\mathbf{K}$. & 12 & 88 & 12.9 & 98 & 33 & 95 \\
\hline V. M. & 25 & 75 & 16.1 & 106 & 41 & 89 \\
\hline I. P. & 16 & 84 & 10.8 & 90 & 32 & 98 \\
\hline J. S. & 24 & 76 & 13.6 & 99 & 25 & 93 \\
\hline M. N. & 24 & 76 & 10.4 & 102 & 33 & 100 \\
\hline A. $\mathrm{N}$. & 24 & 76 & 18.0 & 89 & 39 & 72 \\
\hline D. J. & 13 & 87 & 19.6 & 92 & 19 & 118 \\
\hline R. C. & 28 & 72 & 14.4 & 110 & 22 & 95 \\
\hline G. N. & 55 & 45 & 7.7 & 134 & 21 & 95 \\
\hline B. G. & 5 & 95 & 11.6 & 86 & 25 & 86 \\
\hline Mean $\pm \mathrm{SE}$ & $23 \pm 4$ & $77 \pm 4$ & $13.5 \pm 1.2 \ddagger$ & $101 \pm 4.5$ & $29 \pm 2.5$ & $94 \pm 4$ \\
\hline \multicolumn{7}{|c|}{ Nonpregnant } \\
\hline M. E. $\delta$ & 11 & 89 & 6.5 & 69 & 42 & 98 \\
\hline C. $\mathrm{K} . \S$ & 0 & 100 & 8.9 & 61 & 32 & 97 \\
\hline J. F.\| & 7 & 93 & 5.2 & 71 & 25 & 108 \\
\hline P. W.\| & 7 & 93 & 9.6 & 81 & 41 & 107 \\
\hline Mean $\pm \mathrm{SE}$ & $6 \pm 2$ & $94 \pm 2$ & $7.6 \pm 1.0$ & $71 \pm 4$ & $35 \pm 4$ & $103 \pm 3$ \\
\hline \multicolumn{7}{|l|}{ Male } \\
\hline \multicolumn{7}{|c|}{ Seven values\| (five for tetrahydroaldosterone) } \\
\hline Mean $\pm \mathrm{SE}$ & $3.7 \pm 0.6$ & $96.3 \pm 0.6$ & $7.1 \pm 0.7$ & $75 \pm 5$ & $36 \pm 7$ & $117 \pm 6$ \\
\hline
\end{tabular}

${ }^{*}{ }^{14} \mathrm{C}$ and ${ }^{8} \mathrm{H}$ expressed as per cent of oral and intravenous doses, respectively.

$\ddagger$ Six other pregnant subjects in a different previously unpublished series gave $13.1 \pm 1.8$ (SE) $\%$ for this value.

$\$$ Determined in same series and by same methods as urine from pregnant subjects.

|| Previously published as part of another series (5). 
pregnant subjects $(P=0.05$ and 0.01 for pregnant compared with nonpregnant female and male values, respectively). The values for the two nonpregnant groups were not significantly different. The mean value for these six pregnant subjects of $13.1 \pm 1.8$ ( $\mathrm{SE}$ ) \% was in good agreement with the corresponding value obtained by Jones and coworkers (1) for six pregnant women (13.3 \pm $1.7[\mathrm{SE}]$ as per cent of intravenous dose) and $13.5 \pm 1.2$ ( $\mathrm{SE}$ ) as per cent of intravenous dose for the 10 pregnant subjects in the present series who were given both oral and intravenous aldosterone. The combined value for the 16 pregnant subjects investigated in the present series was $13.4 \pm$ 0.9 (SE) \%, which was significantly higher $(P<$ 0.001 ) than the 11 combined nonpregnant value of $7.3 \pm 0.5$ ( $\mathrm{SE}$ ) \%. The recovery of labeled aldosterone added to the urine after neutral extraction and carried through the procedure was 56 and $57 \%$ in normal urine and 59 and $67 \%$ from pregnant urine. In previous work, Underwood and Tait (3) determined recoveries of 69 and $68 \%$ for urine from nonpregnant subjects by the same procedure. The recoveries from pregnancy urine are therefore not significantly different from normal urine and cannot account for differences observed. The values quoted are all uncorrected for losses. These losses cannot be corrected for in a rigorous manner without the use of labeled conjugate as indicator. This is not generally available in suitable amounts. However, comparisons of estimates carried out in the same laboratory will be valid.

The proportion of oral $\left({ }^{14} \mathrm{C}\right.$ fraction of administered dose) compared with the intravenous $\left({ }^{3} \mathrm{H}\right.$ fraction of administered dose) dose excreted $\left({ }^{14} \mathrm{C} /\right.$ ${ }^{3} \mathrm{H}$ ratio) gives the relative contributions of the oral and the intravenously administered aldosterone to the urinary metabolites. This gives a measure of the proportionate influence of the splanchnic bed on administered aldosterone. When the ${ }^{14} \mathrm{C} /{ }^{3} \mathrm{H}$ ratio ( $r$ ) of urinary free aldosterone is measured, the splanchnic extraction (1-r) may be calculated. The splanchnic extraction is that portion of aldosterone either metabolized or removed from the splanchnic circulation in one passage. The ${ }^{14} \mathrm{C} /{ }^{3} \mathrm{H}$ ratio ( $\mathrm{r}$ ) (both isotopic yields expressed as a per cent of administered dose) of urinary free aldosterone was $22.6 \pm 4.3$ (SE) \% for the 10 pregnant subjects, which is significantly higher than the corresponding values for the four nonpregnant females $(6.3 \pm 2.3 \quad$ [SE] \% $\quad(P=$ $0.05)$ and the seven males investigated previously $(3.7 \pm 0.6[\mathrm{sE}] \%)(P<0.01)(4,5)$. The value for the 10 pregnant subjects was significantly higher $(P=0.001)$ than the combined 11 nonpregnant value of $4.6 \pm 0.9$ (SE) \%. Similarly the calculated splanchnic extraction of $77 \pm 4$ (SE) \% for the pregnant subjects (given by per cent (1-r)) $(4,5)$ was significantly lower than the corresponding value calculated for the nonpregnant subjects of $93.8 \pm 2.3$ ( $\mathrm{SE}$ ) \% for the four females and $96.3 \pm 0.6(\mathrm{SE}) \%$ for the seven males or $95.4 \pm 0.9$ (SE) \% for the combined 11 nonpregnant values.

Altered aldosterone metabolism might also appear as a changed proportion of intravenous aldosterone $-{ }^{3} \mathrm{H}$ appearing as tetrahydroaldosterone glucuronide in the urine. However the per cent of the administered intravenous dose of aldosterone $-{ }^{3} \mathrm{H}$ as tetrahydroaldosterone was $29 \pm 2.4$ (SE) \% for the 10 pregnant subjects which was not significantly lower than the combined mean for the corresponding values in the nine male and female value of $35.4 \pm 3.8$ (SE) \% ( $P$ value of 0.1 ). The male and nonpregnant female values were also not significantly different.

The ${ }^{14} \mathrm{C} /{ }^{3} \mathrm{H}$ ratio of the urinary tetrahydroaldosterone gives an indication of the relative contribution of splanchnic and extrasplanchnic contribution to this urinary metabolite. The ${ }^{14} \mathrm{C} /{ }^{3} \mathrm{H}$ ratio of the tetrahydroaldosterone was $94.1 \pm 3.7$ (SE) \% for the 10 pregnant subjects which is significantly lower than the combined results for the nine (two samples were lost) nonpregnant values of $110.6 \pm 4.1$ (SE) \% $(0.05>P>0.01)$. The male and nonpregnant female values were not significantly different (Table II).

The proportion of oral compared to intravenous dose excreted as aldosterone released from the acid-labile conjugate which is the major extrahepatic route of metabolism indicates the proportionate change taking place in this route of metabolism. The ${ }^{14} \mathrm{C} /{ }^{3} \mathrm{H}$ ratio of the aldosterone released by mild acid hydrolysis was $100.6 \pm 4.5$ (SE) \% which was significantly higher $(P<0.01)$ than the 11 combined nonpregnant value of $73.1 \pm$ 3.3 (SE) $\%$. The male and nonpregnant female values were again not significantly different (Table II). 


\section{DISCUSSION}

This study confirms the work of Jones et al. (1) that there is an increased conversion of aldosterone to urinary aldosterone 18-glucuronide in pregnancy. The results of Watanabe et al. (2) who could not demonstrate this effect may be explained by failure to study a large enough group of subjects.

The calculated splanchnic extraction of aldosterone in pregnancy is $77 \%$ which is significantly below the observed $90 \%$ in nonpregnant patients (measured both by direct hepatic vein catheterization [7] and indirect calculation as in the present study). Theoretically this lowered splanchnic extraction could be the result of increased aldosterone binding to plasma proteins other than to albumin (splanchnic extraction of steroids is not usually lowered by albumin binding [8]). However, although aldosterone does demonstrate increased plasma protein binding following unusually high doses of estrogen, there is no increase in pregnancy (8). Abnormally elevated estrogen secretion in the present pregnancy studies was ruled out by studying urinary estrogen excretion by the method of Brown ${ }^{2}$ (9). All values were in the normal range, and no correlation could be demonstrated between the excretion of estrogen and calculated splanchnic extraction (Tables I and II). This unaltered binding would therefore suggest a reduction of the hepatic metabolism of aldosterone. This could be similar to cortisol disappearance in pregnancy and after estrogen treatment, in which the calculated metabolic clearance rate of free and albumin-bound cortisol is reduced $(8,10)$ without alteration in hepatic blood flow (11). This is apparently a hepatic cellular effect.

The metabolic clearance rate of aldosterone is not significantly different in pregnancy from that of nonpregnant subjects (12). The criticism by Braunsberg and James (13) that a different model should have been used overlooked that the metabolic clearance rate was measured after prolonged continuous infusion, which gave the same result. This finding indicated that additional possible compartments in pregnancy did not affect the determination in pregnancy. This has been discussed in detail by one of us (14). The combined results

2 These determinations were kindly carried out by Dr. J. E. Roberts, Worcester Foundation. for 13 nonpregnant subjects by both single injection and continuous infusion was $1631 \pm 106$ (SE) liters of plasma per day and $1543 \pm 113$ (SE) liters of plasma per day (15 pregnant subjects). The expected decrease in metabolic clearance rate due to the reduced splanchnic extraction (from 95 to $77 \%$ ) with unchanged hepatic blood flow (11) would have been about 300 liters/day and it seems probably would have been detected. This finding suggests that there is a decrease in splanchnic clearance (unchanged total metabolic clearance) and an increase in extrasplanchnic clearance of aldosterone in pregnancy. This increase in extrasplanchnic clearance cannot be compensatory to changes in splanchnic clearance. However, renal blood flow is increased in pregnancy (15) and production of the 18-glucuronide metabolite from aldosterone by the kidney might thereby be raised. The fetus and the placenta could also be responsible for the increase in extrasplanchnic clearance; however, no relevant direct data are available to prove or disprove either possibility.

The increase in formation of aldosterone 18glucuronide could be due to the increased production of this metabolite by extrasplanchnic tissues. The kidney is now known to contribute an appreciable portion to the total production of this metabolite (16). In cirrhosis the increased formation of this metabolite has been proposed as due to lowered splanchnic clearance with proportionate increase in production of the metabolite by the kidney. However, in pregnancy, the splanchnic clearance is probably lowered by only $20 \%$, and the proportion of the aldosterone 18-glucuronide made from an intravenous dose of hormone is doubled $(7-13 \%)$ (Table II). It is unlikely therefore that this is the major reason for this effect.

Oral aldosterone is converted less efficiently to urinary 18-glucuronide than intravenously administered hormone in nongravid subjects (17). This finding was confirmed experimentally and theoretically by Flood et al. (6). Oral aldosterone appears to be nearly completely extracted by the liver, whereas the intravenous aldosterone is also converted to the 18-glucuronide extrasplanchnically in the kidney. If extrasplanchnic formation of this conjugate were increased in the pregnant woman, and the other factors were unaltered, the ${ }^{14} \mathrm{C} /{ }^{3} \mathrm{H}$ ratio of the urinary aldosterone 18 -glucuronide would be reduced. The isotope ratio was, 


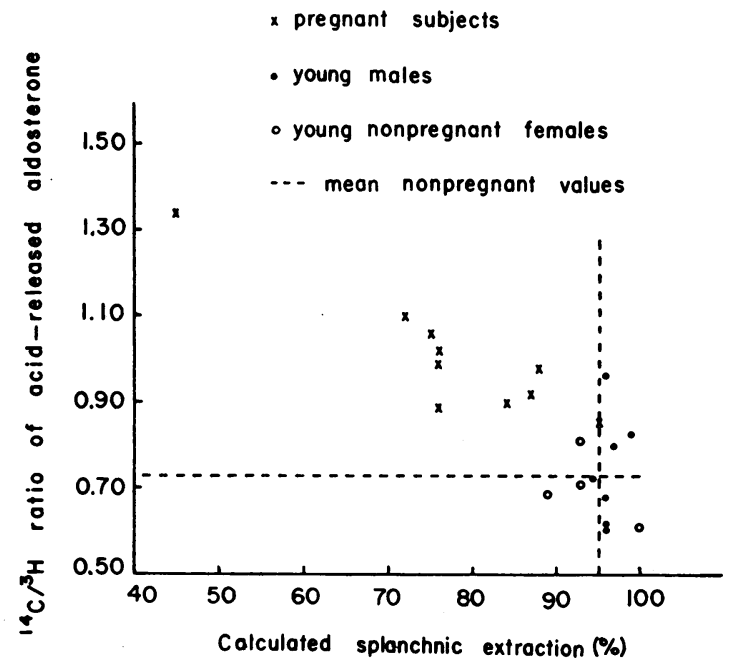

FigURE $1{ }^{14} \mathrm{C} /{ }^{3} \mathrm{H}$ ratio of acid-released aldosterone (from oral ${ }^{14} \mathrm{C}$ and intravenous aldosterone- ${ }^{3} \mathrm{H}$ ) plotted against the calculated splanchnic extraction for pregnant and nonpregnant subjects.

however, higher in the pregnant than the nonpregnant subjects. This could be accounted for by reduced splanchnic extraction. But it can be seen that the ${ }^{14} \mathrm{C} /{ }^{3} \mathrm{H}$ ratio when plotted against calculated splanchnic extraction is linearly related (Fig. 1 ) ; and if this is extrapolated to normal nonpregnant values, the ratio would still be high. Therefore lowered splanchnic extraction cannot entirely explain this increase in the isotope ratio, or as previously discussed, in the urinary ${ }^{3} \mathrm{H}$ yield, of the aldosterone 18-glucuronide. It seems therefore that at least some of the increased yield is due to a higher rate of formation of the conjugate in the liver.

These conclusions from the ${ }^{14} \mathrm{C} /{ }^{3} \mathrm{H}$ ratio assume that the extent of formation of aldosterone glucuronide from the oral dose of aldosterone before the hormone reaches the liver is the same in pregnant and nonpregnant subjects. Both aldosterone 18-glucuronide and 17-isoaldosterone 18-glucuronide are formed in the splanchnic bed before oral doses of aldosterone and 17 -isoaldosterone reach the liver (5). If this occurs, the splanchnic extraction would be expected to be reduced, but the ${ }^{14} \mathrm{C} /{ }^{3} \mathrm{H}$ ratio in the urinary aldosterone 18 -glucuronide would be increased, findings which were also demonstrated for 17-isoaldosterone (5). One subject (G. N.) whose splanchnic extraction was low $(45 \%)$ had a high $(134 \%){ }^{14} \mathrm{C} /{ }^{3} \mathrm{H}$ ratio for the acid-labile conjugate, a fact which tends to confirm this conclusion. We have no other reasonable explanations for such ratios than that there is metabolism of the orally administered compounds to the 18-glucuronides before they reach the liver. If such formation were increased in pregnancy the ratio would be raised for this reason and not necessarily because of increased hepatic formation. The present experimental approach cannot definitely decide this point.

Excretion of tetrahydroaldosterone (as a per cent of intravenously injected aldosterone- ${ }^{3} \mathrm{H}$ ) is decreased by administration of estrogens to nonpregnant females (18). It might be expected that the hepatic formation of tetrahydroaldosterone would be reduced in pregnancy, with a compensatory increase in the aldosterone 18-glucuronide by the liver. The splanchnic extraction is decreased, but the conversion of intravenously administered aldosterone- ${ }^{3} \mathrm{H}$ to tetrahydroaldosterone is not lowered (Table II). Formation of tetrahydroaldosterone may be reduced by the liver and increased by extrasplanchnic sites. This possibility would also explain the lowered ${ }^{14} \mathrm{C} /{ }^{3} \mathrm{H}$ ratio of this metabolite observed. As the kidney does not form appreciable amounts of tetrahydroaldosterone, this increase in extrasplanchnic production most likely reflects fetoplacental contribution.

\section{ACKNOWLEDGMENTS}

This work was supported by U. S. Public Health Service Grants AM-03179 and HD-02378. The pregnant subjects were studied in the Perinatal Clinical Research Center supported by grant FR-00210. Dr. Tait is a holder of U. S. Public Health Service Career Award GM-K618322.

\section{REFERENCES}

1. Jones, K. M., R. Lloyd-Jones, A. Riondel, J. F. Tait, S. A. S. Tait, R. D. Bulbrook, and F. C. Greenwood. 1959. Aldosterone secretion and metabolism in normal men and women and in pregnancy. Acta Endocrinol. 30: 321 .

2. Watanabe, M., C. I. Meeker, M. J. Gray, E. A. H. Sims, and S. Solomon. 1963. Secretion rate of aldosterone in normal pregnancy. J. Clin. Invest. 42: 1619.

3. Underwood, R. H., and J. F. Tait. 1964. Purification, partial characterization and metabolism of an acid labile conjugate of aldosterone. J. Clin. Endocrinol. Metab. 24: 1110.

4. Flood, C., C. Gherondache, G. Pincus, J. F. Tait, S. A. S. Tait, and S. Willoughby. 1967. The metabolism and secretion of aldosterone in elderly subjects. J. Clin. Invest. 46: 960. 
5. Flood, C., G. Pincus, J. F. Tait, S. A. S. Tait, and S. Willoughby. 1967. A comparison of the metabolism of radioactive 17-isoaldosterone and aldosterone administered intravenously and orally to normal human subjects. J. Clin. Invest. 46: 717.

6. Flood, C., D. S. Layne, S. Ramcharan, E. Rossipal, J. F. Tait, and S. A. S. Tait. 1961. An investigation of the urinary metabolites and secretion rates of aldosterone and cortisol in man and a description of methods for their measurement. Acta Endocrinol. $36: 237$.

7. Bougas, J., C. Flood, B. Little, J. F. Tait, S. A. S. Tait, and R. Underwood. 1964. Dynamic aspects of aldosterone metabolism. In Aldosterone. E. E. Baulieu and P. Robel, editors. Blackwell Scientific Publications, Ltd., Oxford. 25.

8. Meyer, C. J., D. S. Layne, J. F. Tait, and G. Pincus. 1961. The binding of aldosterone to plasma proteins in normal, pregnant and steroid treated women. $J$. Clin. Invest. 40: 1663.

9. Brown, J. B. 1960 . The determination and significance of the natural estrogens. In Advances in Clinical Chemistry. Harry Sobotka and C. P. Stewart, editors. Acadamic Press Inc., New York: 3: 157.

10. Yates, F. E., and J. Urquhart. 1962. Control of plasma concentrations of adrenocortical hormones. Physiol. Rev. 42 : 359.

11. Munnell, E. W., and H. C. Taylor, Jr. 1947. Liver blood flow in pregnancy-hepatic vein catheterization. J. Clin. Invest. 26: 952.

12. Tait, J. F., B. Little, S. A. S. Tait, and C. Flood. 1962. The metabolic clearance rate of aldosterone in pregnant and nonpregnant subjects estimated by both single-injection and constant-infusion methods. $J$. Clin. Invest. 41 : 2093.

13. Braunsberg, H., and V. H. T. James. 1967. Mathematical analysis of experiments with labeled hormone tracers: problems of interpreting tissue radioactivity. J. Clin. Endocrinol. 27: 1176.

14. Tait, J. F. 1966. Discussion to conjugation and excretion of aldosterone: testing of models with an analog computer. In Steroid Dynamics. G. Pincus, T. Nakao, and J. F. Tait, editors. Academic Press Inc., New York. 355.

15. Sims, E. A. H., and K. E. Krantz. 1958. Serial studies of renal function during pregnancy and the puerperium in normal women. J. Clin. Invest. 37: 1764.

16. Luetscher, J. A., C. A. Camargo, R. A. Cheville, E. W. Hancock, A. J. Dowdy, and G. W. Nokes. 1966. Conjugation and excretion of aldosterone: testing of models with an analog computer. In Steroid Dynamics. G. Pincus, T. Nakao, and J. F. Tait, editors. Academic Press Inc., New York. 341.

17. Bledsoe, T., G. W. Liddle, A. Riondel, D. P. Island, D. Bloomfield, and B. Sinclair-Smith. 1966. Comparative fates of intravenously and orally administered aldosterone: evidence for extrahepatic formation of acid-hydrolyzable conjugate in man. J. Clin. Invest. 45: 264.

18. Layne, D. S., C. J. Meyer, P. S. Vaishwanar, and G. Pincus. 1962. The secretion and metabolism of cortisol and aldosterone in normal and in steroidtreated women. J. Clin. Endocrinol. Metab. 22: 107. 